\title{
Erratum
}

\section{Reducing Light and Sound in the Neonatal Intensive Care Unit: An Evaluation of Patient Safety, Staff Satisfaction, and Costs}

Walsh-Sukys M, Reitenbach A, Hudson-Barr D, DePompei P. J Perinatol 2001;21:230-235.

Since publication of the above paper, a typesetting error in Figure 1 has been identified. The correct Figure 1 is reproduced below.

Tive tisor:

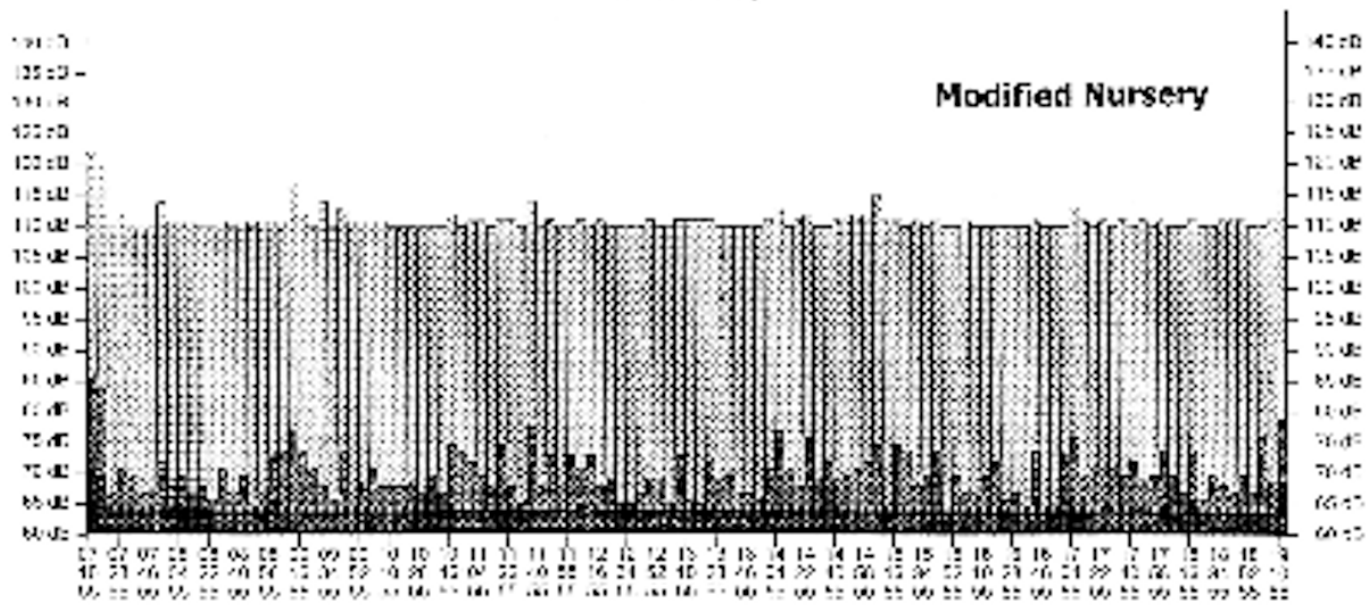

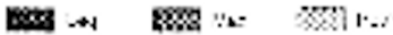

Lodi is lomaceds 200 !

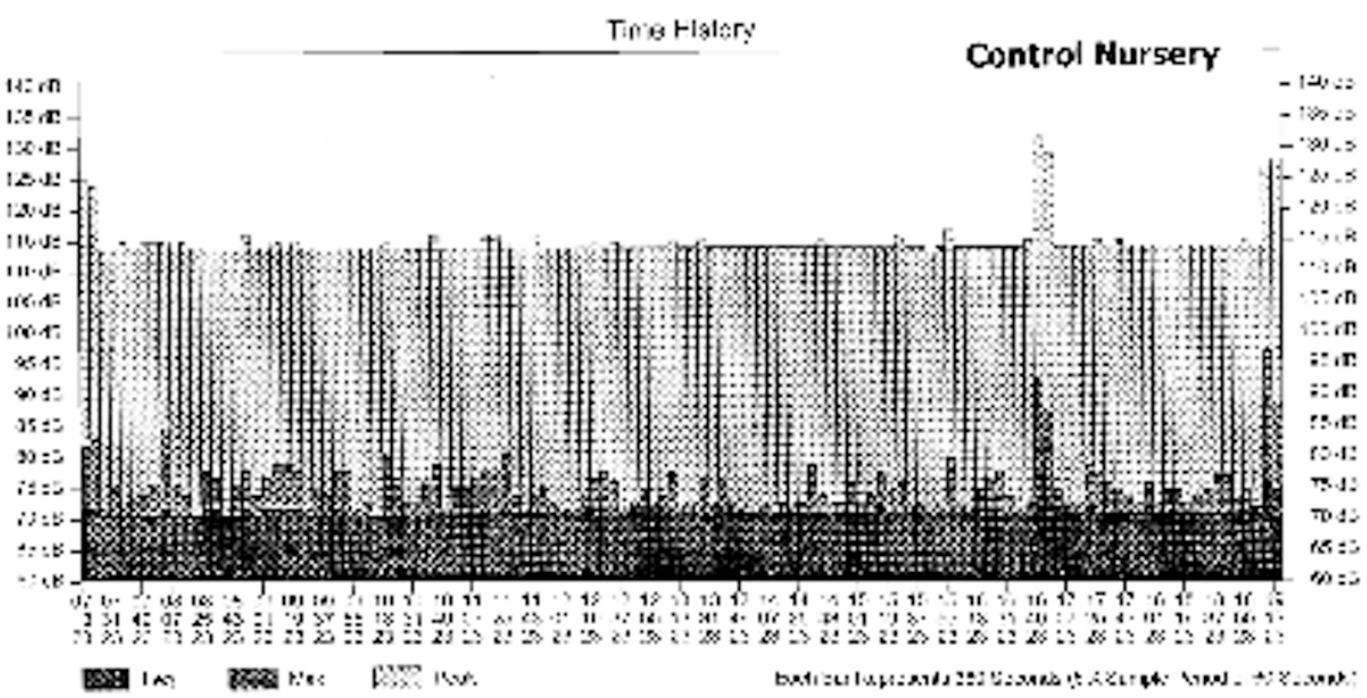

Rainbow Babies and Children's Hospital, 11100 Euclid Avenue, Cleveland ,OH.

Address correspondence and reprint requests to $\mathrm{Dr}$ M. Walsh-Sukys, Rainbow Babies and

Children's Hospital, 11100 Euclid Avenue, Cleveland, OH 44106-6010. 